Published in final edited form as:

Patient Educ Couns. 2018 December ; 101(12): 2105-2110. doi:10.1016/j.pec.2018.07.022.

\title{
Accuracy and congruence of physician and adolescent patient weight-related discussions: Teen CHAT (Communicating health: Analyzing talk)
}

\author{
Michael E. Bodnera, ${ }^{a}$, Pauline Lyna ${ }^{b}$, Truls Østbye ${ }^{\mathrm{i}}$, Terrill Bravenderd, Stewart C. \\ Alexandere, James A. Tulsky,g, Pao-Hwa Lin ${ }^{\mathrm{h}}$, and Kathryn I. Pollak ${ }^{\mathrm{f}, \mathrm{c}}$ \\ aSchool of Human Kinetics, Trinity Western University, Langley, Canada \\ ${ }^{b}$ Cancer Control and Populations Sciences, Duke Cancer Institute, Durham, USA \\ 'Department of Population Health Sciences, Duke School of Medicine, Durham, USA \\ ${ }^{\mathrm{d} D e p a r t m e n t}$ of Pediatrics, University of Michigan, Ann Arbor, USA \\ eDepartment of Consumer Science, Purdue University, Lafayette, USA \\ fDepartment of Psychosocial Oncology and Palliative Care, Dana Farber Cancer Institute, Boston, \\ USA \\ 9Department of Medicine, Division of Palliative Medicine, Brigham and Women's Hospital, Boston, \\ USA \\ hDepartment of Medicine, Duke University Medical, Durham, USA \\ iDepartment of Community and Family Medicine, Duke University, Durham, USA
}

\begin{abstract}
Objective: We assessed the accuracy and congruence of recall of weight topics during clinical encounters between adolescent patients with overweight/obesity and physicians (randomized to Motivational Interviewing education vs. control arm).

Methods: We audio recorded 357 clinic encounters and coded topics of weight, physical activity (PA), breakfast, and fast food. We assessed recall accuracy/congruence. Generalized estimation equation modeling assessed associations between selected factors and recall accuracy.

Results: Accuracy for physicians was: weight (90\%), PA (88\%), breakfast (77\%) and fast food (70\%). Patient accuracy was: weight (94\%), PA (94\%), breakfast (73\%) and fast food (61\%). Physician/patient congruence was: weight (89\%), PA (90\%), breakfast (71\%) and fast food (67\%). Use of a reminder report indicating adolescent's weight behaviors in the physician control group resulted in increased adolescent $(\mathrm{p}=0.02)$ and physician accuracy $(\mathrm{p}=0.05)$ for fast food.
\end{abstract}

\footnotetext{
"Corresponding author at: School of Human Kinetics, Trinity Western University Langley, British Columbia, V2Y 1Y1, Canada. Conflicts of interest

None

Consent

I confirm all patient/personal identifiers have been removed or disguised so the patient/person(s) described are not identifiable and cannot be identified through the details of the story.
} 
Adolescents were more likely to recall discussions of fast food (odds ratio, 0.87; 95\% CI, $0.77-$ 0.97 ) as encounter time decreased; male adolescents were less likely to recall breakfast than females (odds ratio, 0.52; 95\% CI, 0.28-0.95).

Conclusion: Adolescents and physicians recall weight and PA more often, perhaps indicating greater engagement in these topics.

Practice Implications: Reminder reports might possibly enhance discussion and recall of diet related messages.

\section{Keywords}

Physicians; Adolescents; Overweight; Obesity; Communication; Audio-recording

\section{Introduction}

Overweight and obesity among U.S. adolescents have risen to (or remain at) epidemic levels [1-4]. Excessive weight gain in adolescents is associated with increased risk of adverse health consequences including metabolic dysfunction, insulin resistance, hypertension and early markers of cardiovascular disease [5,6]. Further, adolescents who are overweight/obese tend to become overweight/obese adults [7]. Helping overweight/obese adolescents achieve and maintain a healthy weight is a healthcare priority.

The 2007 Expert Committee on Pediatric Obesity's chronic care model approach to address pediatric overweight/obesity encourages physicians and pediatricians to communicate weight-related messages during clinical care encounters to help patients adopt behaviors favorable to achieving a healthy weight [8]. Based on available evidence, the Committee advocates that weight-related messages should include (1) limiting the consumption of sugar-sweetened beverages (2) limiting screen time to $\mathcal{s}$ h/day (3) eating breakfast daily (4) limiting fast food (5) eating the recommended quantities of fruits and vegetables and (6) promotion of at least $60 \mathrm{~min}$ of moderate to vigorous physical activity (PA) [8].

To help facilitate the delivery of weight related messages, physicians have been encouraged to use communication techniques such as motivational interviewing (MI) [8]. Some have suggested that specific clinical cues in the form of 'prompts' or 'alerts' might help remind or guide physicians to address topics, including those pertinent to patient weight. These prompts might take the form of a reminder card, 'best practice' alert using electronic medical records, or printed automated clinical reminders [9,36,37]. Pollak et al. [10] incorporated the use of a reminder report in the form of a written 'Summary Report' that itemized behaviors related to weight (e.g. physical activity, diet-related aspects) to prompt physicians to address these behaviors with their adolescent patients.

For adolescents to engage in healthy lifestyle habits related to weight loss or weight management, they need to receive, retain, and recall messages from their physicians. Further, physicians need to know that their health messages are received. However, research findings show that weight-related topics reported by physicians and adolescent patients who are overweight/obese during clinical encounters show marked variation. Physician reports based on chart reviews from the 2005-2009 National Ambulatory Medical Care Survey and 
National Hospital Ambulatory Medical Care Surveys suggest generally infrequent message delivery for topics of weight reduction, diet and exercise [11,12]. Patient reports vary, depending on the health topic. For example, a large convenience sample $(n=2305)$ of adolescents from New York state reported exercise (83-88\%) and healthy eating discussions (67-85\%) from their physician [22]. However, findings from the 2001-2007 Medical Expert Panel Survey and others show markedly less exercise (40-69\%) and dietary advice (44$62 \%)$ delivered from physician or other health professionals. [23,24].

Inconsistencies in reports of weight related topics in clinical encounters may be due to variations in preventive practices by the individual primary care health professional [12]. Further, studies using self-report mechanisms (e.g., telephone surveys, chart reviews) to assess weight messages leave room for the influence of potential recall bias or memory decay [13-15]. More objective measurement techniques, such as audio recordings, can help to verify the incidence of message delivery during clinical visits and patient and physician recall thereafter [16]. Klein et al. [17] showed that adolescents have demonstrated accurate recall of exercise and to a lesser extent, diet and weight topics when audio recordings were compared to post-visit follow-up telephone surveys. However, this study was not specific to adolescents with overweight/obesity, nor did it assess physician recall. Recall of weightrelated topics during such clinical visits by adolescent patients and their attending physician remains understudied [18].

The purpose of this study was to assess the accuracy and congruency of recall of weightrelated messages (i.e., weight, PA, breakfast, fast food consumption) by adolescent patients who are overweight/obese and their attending physicians using independent verification (audio recordings). We also assessed patient, physician or visit-related factors associated with the accuracy of adolescent or physician recall of weight-related messages and hypothesized that the use of a written Summary Report of patient's weight related behaviors to guide the clinical encounter would be associated with greater recall accuracy by adolescents and physicians, compared to without the use of a Summary Report.

\section{Methods}

\subsection{Teen CHAT overview}

We analyzed data from the Teen CHAT (Communicating Health: Analyzing Talk) study, a randomized controlled trial designed to improved communication between physicians and adolescents who are overweight/obese regarding healthy weight by analyzing audio recordings of clinic encounters [10]. The Teen CHAT Trial had three phases: Baseline, Intervention, and Summary Report [10] with new patients in each phase. We audio recorded physicians and their adolescent patients in the Baseline phase. We then randomized physicians to a control or MI-trained intervention (Intervention Phase) group. In the Intervention phase, we used the Baseline audio recordings to develop a personalized online training program designed to enhance motivational interviewing (MI) behaviors of physicians to help them counsel for behaviors related to weight. This training program was about 60 min long and incorporated personalized audio clips from physicians' Baseline patient encounters. This MI intervention is described in greater detail elsewhere [19]. Both control and Intervention phase physicians continued through to a Summary Report phase. In 
the Summary Report phase both groups of physicians (control and MI intervention) and their patients received a Summary Report to guide their discussion. This report briefly itemized patients' modifiable behaviors pertaining to weight including weight, physical activity, consumption of breakfast and fast food.

\subsection{Recruitment}

Descriptions regarding physician and patient recruitment are detailed elsewhere [20]. Briefly, we recruited 49 primary care physicians from 8 community- and 3 academic-based practices. After completion of the Baseline, three of these 49 physicians were withdrawn (one physician had no patient visits) leaving 45 physicians randomized to either control or Intervention. Physicians provided written informed consent, completed a baseline survey and provided their electronic signature (for recruitment letters to their patients) [10].

A HIPAA waiver of authorization was obtained for research staff to review clinic files of adolescents who were overweight/obese (z-scores $\geq 85$ th percentile) of participating physicians. Next, we mailed consent forms along with the signed letter from the physician to patients and parents. To conceal that the study was about weight, the letter described the study as an investigation as to how physicians addressed preventive health with their patients. We gave parents or adolescents the option to opt out (toll-free number). We called parents a week later to screen for eligibility, obtain verbal consent and ask permission to contact the patient. Thereafter, we conducted a baseline questionnaire that included questions related to demographic factors as well as questions related to weight, nutrition and physical activity. To further conceal that the study was about weight, Baseline questions also included those related to smoking, drug use, and sexual activity.

\subsection{Clinic visit}

Research staff met with the parent and patient at the clinic on the day the visit was audio recorded and obtained written consent/assent. Patients were eligible if they were 12-18 years of age, spoke English, not pregnant, cognitively competent, and had telephone access.

Immediately following the clinical visit, physicians and patients completed written questionnaires querying 'yes' or 'no' if the topics of weight, PA, breakfast or fast food were brought up by the physician. Similar to the Baseline survey, weight related questions in the post-visit were embedded with questions about other risk behaviors.

All study procedures were approved by the Duke University Health System Institutional Review Board (IRB).

\subsection{Data analysis}

For the audio recordings, coders confirmed weight-related topics raised either by physicians or patients: weight, PA, breakfast and fast food. A detailed codebook provided specific instructions, including precise definitions of codes and examples. Coders received $30 \mathrm{~h}$ of rigorous training to identify weight-related content until a high level of reliability was achieved [21]. 
Audio recordings were cross-tabulated with physician and adolescent post-visit survey self reports to assess accuracy and congruence. Recall was appraised as "accurate" when selfreported presence or absence of weight, PA, breakfast, or fast food topics were verified by coded audio-recorded content. "Congruence" occurred when both physician and patient reported that weight, PA, breakfast or fast food was or was not discussed in the encounter.

\subsection{Statistical analysis}

Descriptive statistics (frequencies or mean (SD)) described physician, patient and clinic sociodemographics and characteristics. Generalized estimation equation modeling tested for the effect of the Summary Report and other factors associated with accuracy. For all analyses, we used SAS for Windows (Version 9.4: SAS Institute, Cary, NC). We fit models using Generalized Estimate Equation (GEE) to account for clustering of patients within physician. For all models, the following factors were tested: interaction term for Phase (Intervention or Summary Report) and treatment arm (MI or control) and characteristics for physician (race and gender), adolescent (race, gender and baseline BMI-percentile) and length of encounter. Statistical significance was set at 0.05 .

\section{Results}

\subsection{Accuracy and congruence}

Patient and physician characteristics are presented in Table 1. According to audio recordings, in 357 clinical encounters, physicians and patients discussed weight 336 times (94\%), PA 335 times (94\%), breakfast 176 times (49\%) and fast food discussed 120 times (34\%). Overall, both patients and physicians were accurate with respect to weight and PA recall. In encounters coded as containing weight and PA, accuracy was high for both adolescents (94\% and 94\%, respectively) and physicians (90\% and 88\%, respectively). For breakfast and FF recall, adolescent and physician reports were less accurate. Adolescents' accuracy was $73 \%$ and $61 \%$ for breakfast and fast food, respectively; for physicians, accuracy was $77 \%$ and $70 \%$, respectively. Adolescents and physicians were strongly congruent for weight (89\%) and PA (90\%), but slightly less so for breakfast (71\%) and fast food $(67 \%)$. Both adolescents and physicians were more accurate when a topic was discussed than when it was not (Table 2): for weight, 97 and 92\%, for PA, 99 and 91\%, for breakfast, 96 and $88 \%$, and for fast food 93 and $89 \%$, respectively.

\subsection{Models}

We modeled factors predicting patient and physician accuracy for breakfast and fast food, but not for weight nor PA given the lack of variability in accuracy of those coded messages. Neither control nor MI arms of the phases were associated with accuracy nor congruence for breakfast or congruence for fast food.

Table 3 describes factors associated with adolescent accuracy for fast food and breakfast. For fast food, there was a significant arm by phase interaction ( $\mathrm{p}<0.05$ ). In the control arm, adolescents with the Summary Report were more accurate compared to those without the Summary Report (odds ratio, 2.70; 95\% CI, 1.45-5.05) but not the MI trained group (odds ratio, $0.84 ; 95 \% \mathrm{CI}, 0.45-1.57)$. The shorter the length of the encounter, the more likely 
adolescents recalled fast food messages (odds ratio, $0.87 ; 95 \% \mathrm{CI}, 0.77-0.97$ ). For breakfast, adolescents were half as likely to be accurate if they were male (odds ratio, $0.52 ; 95 \% \mathrm{CI}$, $0.28-0.95$ ) and almost twice as likely to be accurate if their physician was white compared to non-white (odds ratio, 1.93; 95\% CI, 1.28-2.90).

Factors associated with physician accuracy for fast food and breakfast are described in Table 4. Similar to adolescents, for fast food there was a significant arm by phase interaction ( $\mathrm{p}=$ 0.05 ) with respect to the Summary Report for the control group (odds ratio, 2.04; 95\% CI, 1.28-3.25) but not the MI trained group (odds ratio, 0.82; 95\% CI, 0.38-1.77). For breakfast, physicians were three times as likely to be accurate if the physician was white compared to non-white (odds ratio, 3.03; 95\% CI, 1.68-2.48).

\section{Discussion and conclusion}

\subsection{Discussion}

This is the first study to assess recall of weight related messages by both physician and adolescent patients who are overweight/obese using independent verification. There were four key findings. First, the topics of PA and weight were discussed most often, and physicians and their overweight/obese adolescents were highly accurate and congruent with respect to self-reported recall of these messages. Breakfast and fast food were discussed with less frequency; both physician and adolescents were less accurate and congruent in terms of recall. Second, the provision of a written Summary Report may help with increased recall accuracy for messages pertaining to diet, particularly fast food. Third, for patients, the shorter the length of the clinical visit, the more likely they accurately recalled a fast food message. Finally, males appeared to be less accurate than females in terms of breakfast recall accuracy.

Our findings that topics related to weight and PA occur frequently are somewhat discordant with larger national medical surveys that show that such topics occur with less frequency; our findings are more consistent with smaller sample studies. However, our findings of lower fast food and breakfast topic frequencies are similar to those reported by such national surveys $[11,12,22-24]$. As is the case with national medical care surveys, data drawn from surveys or charts do not use independent verification and are thus limited to self-report. Further, the length of time (up to a year) that adolescents are required to recall details of a clinical conversation may induce some memory decay. Also, in our study, many of the physicians used their Summary Report to guide their conversation, so they, in essence, had a script to follow. This may explain some of the dissonance between our findings and data related to national surveys. However, Klein et al. [17] reported that adolescent recall of health messages received during clinical visits, as verified by independent means, is largely accurate over two week and six month time periods, and appears to show some temporal stability.

Our use of audio recordings allowed us to verify the recall accuracy of clinical messages, including that of physicians, an understudied population in this regard. It would appear that physicians and patients are highly accurate when they recall weight and PA topics, more so than diet topics. Although breakfast and fast food topics were discussed with less frequency, 
patients and physicians were nevertheless highly accurate when these topics were brought up (audio recording verified), but less accurate when they did not. In approximately half the encounters when a diet topic was not brought up, participants nevertheless thought that it was. Patients were less accurate than physicians in this regard.

Findings showing high congruency for weight and PA yet overestimation for dietary topics not discussed (as verified by audio recording) is enigmatic. High congruence for weight and PA could be explained in part that most of the clinical visits in this study (96\%) were wellchild visits. Given the nature and understanding of the components of a well-child visit, it could be that there was some level of expectation that these topics, specifically that weight and physical activity would be discussed. At the time of the study, only a few practices used electronic medical records that could prompt topics. Most others relied on paper charts that would not contain any potential cuing for topics. However, on the other hand, high congruency for recall of weight and PA topics could be due that those topics occupied a more meaningful space or more time in the context of the visit discussion, enhancing accurate recall.

The false-positive reports for dietary topics (breakfast and fast food) by physicians could be explained in part by social desirability bias. Physicians knew they should have been discussing these topics with their patients who were overweight or obese, even when they did not, and likely accounted for some of the self-reported overestimation.

False memories of discussed diet topics may have arisen due as a result of semantic association to other 'weight-related' topics discussed in the clinical visit. During the clinical visit topics related to weight may have been discussed that were related to breakfast or fast food (e.g., fruits and vegetables, smoothies, or soft drinks). When asked to recall specific topics on the post-visit survey list, physicians or patients might have falsely recalled discussing the semantically related words "breakfast" or "fast food". The more closely the words are related, the greater the chance of providing a false response to post-visit survey $[25,26]$.

Additionally, both physicians and patients had access to the Summary Report. It could be that exposure to the Summary Report in some cases may also have produced a memory artifact that a diet related topic was part of the encounter when it was not.

Further, patients might have seen the Summary Report as an extension of their discussion with their physician, or the essence of their physician's voice. This type of error may yet sustain a positive outcome in that adolescents may act on what was a perceived message.

We also modeled factors that explained increased accuracy regarding breakfast and fast food messages and hypothesized that a Summary Report of patient's weight related behaviors to guide message would increase physician and patient recall accuracy compared to no Summary Report. Only in the control group and only for fast food was there a significant increase in accuracy recall by both patient and physician using this written handout. Reminder reports similar to the one used in our study have shown some utility helping physicians with increasing obesity documentation rates, but not counseling [9]. We have shown that exposure to a simple written report highlighting a patient's weight related 
behaviors may help physicians who are not MI trained discuss diet with their patients, improving recall of fast food topics at least. This simple, practical, stratagem might help patients retain diet related messages post-clinical encounter.

Length of visit was not significant for recall of weight topics with the exception of fast food; for every five-minute increase length of encounter, the less likely a patient recalled fast food as part of the encounter. Adequate time to talk to clinicians during well care visits is associated with greater recall of anticipatory guidance topics by adolescents [27]. In our study it could be that accuracy was highest for topics that likely took more time to discuss and thus had greater retention. Topics that took less time were likely forgotten as encounter duration increased. It is possible that longer duration clinical encounters means a larger plethora of topics discussed, and the more likely patients will not remember everything covered in that encounter.

Interestingly, adolescent males were 50\% less likely to accurately recall breakfast topic as part of the encounter than females. Many overweight adolescent males misperceive their weight and do not engage in weight control (or loss) activities as much as accurate perceivers, and this may include giving some regard to breakfast [28]. However, our accuracy measure assessed verbal process and verbal memory; males consistently underperform in verbal tasks, including memory, as compared to females, which may account for lesser accurate recall of breakfast [29]. Regardless of the reason, this finding is notable given that diet health messages are substantive as they pertain to weight. In adolescents, breakfast consumption is associated with lower BMI [30]. There is also evidence to suggest that the transition from adolescence to young adulthood is characterized by increased frequency of skipping breakfast, a factor associated with greater weight gain during this transition [31].

There were limitations to this study. Participants were aware that the study was about preventive health and so their responses may have been biased (i.e., responded 'yes' that a topic was discussed, when in reality it was not). Further, participants were aware that clinical encounters were being audio recorded. However, audio recording cases and recording devices were inconspicuously placed in all physician offices to offset any visual cue. Our sample of adolescents who were overweight/obese were from a specific geographical locale and all participants were volunteers; as such, there may be some limitations in terms of the generalizability of our findings.

\subsection{Conclusion}

Some physicians may feel that when they bring up topics or messages related to weight, these may not be heard by their patients [32]. However, our findings show that physicians and pediatricians should be encouraged that weight-related health topics, brought up in the course of a clinical visit, are received, retained and recalled by their adolescent patients. Even if these are 'point' encounters, topics related to weight may nevertheless play a substantive part in the ecological approach to the promotion of healthy behaviors as delivered by physicians, perhaps operating as a catalyst for behavior change in pediatric patients [33-35]. 


\subsection{Practice implications}

Practically speaking, given that diet related topics (i.e., breakfast and fast food), key elements of Expert Committee recommendations occur and are recalled with less frequency, physicians may want to consider incorporating a simple written report of self-described adolescent health behaviors to help guide the clinic discussion. This type of instrument shows some utility with respect to the recall of diet-related messages by adolescents.

\section{Acknowledgements}

This work was supported by grants R01HL092403. Clinical Trial Registration: NCT01040975; clinicaltrials.gov. The study sponsor did not have a role in the study design; collection, analysis and interpretation of the data; writing the report; and the decision to submit the report for publication.

\section{References}

[1]. US Preventive Services Task Force, Grossman DC, Bibbins-Domingo K, Curry SJ, Barry MJ, Davidson KW, Doubeni CA, Epling JW Jr, Kemper AR, Krist AH, Kurth AE, Landefeld CS, Mangione CM, Phipps MG, Silverstein M, Simon MA, Tseng CW Screening for obesity in children and adolescents: US preventive services task force recommendation statement. JAMA 2017;317:2417-26. [PubMed: 28632874]

[2]. Lee HE, Lee D, Guang Guo G, Harri KM. US trends in body mass in adolescence and young adulthood, 1959-2002. J. Adolesc. Health 2011;49:601-8. [PubMed: 22098770]

[3]. Ogden CL, Carroll MD, Kit BK, Flegal KM. Prevalence of childhood and adult obesity in the United States, 2011-2012. JAMA 2014;26:806-14.

[4]. Ogden CL, Carroll MD, Lawman HG, Fryar CD, Kruszon-Moran D, Kit BK, Flegal KM. Trends in obesity prevalence among children and adolescents in the United States, 1988-1994 through 2013-2014. JAMA 2016;315:2292-9. [PubMed: 27272581]

[5]. World Health Organization. Obesity: Preventing and Managing the Global Epidemic: Report of a WHO Consultation Geneva, Switzerland 2000.

[6]. Nathan BM, Moran A. Metabolic complications of obesity in childhood and adolescence: more than just diabetes. Curr. Opin. Endocrinol. Diabetes Obes. 2008;15:21-9. [PubMed: 18185059]

[7]. The NS, Suchrindran C, North KE, Popkin BM, Gordon-Larsen P. Association of adolescent obesity with risk of severe obesity in adulthood. JAMA 2010;304:2042-7. [PubMed: 21063014]

[8]. Barlow SE. Expert committee recommendations regarding the prevention, assessment, and treatment of child and adolescent overweight and obesity: summary report. Pediatrics 2007;120:S164, doi:10.1542/peds.2007-2329C. [PubMed: 18055651]

[9]. Shungu N, Miller MN, Mills G, Patel N, de la Paz A, Rose V, Kropa J, Edi R, Levy E, Crenshaw M, Hwang C. Reminder cards improve physician documentation of obesity but not obesity counseling. Fam. Med. 2015;47:789-93. [PubMed: 26545056]

[10]. Pollak KI, Coffman CJ, Tulsky JA, Alexander SC, Østbye T, Farrell D, Lyna P, Dolor RJ, Bilheimer A, Lin P-H, Bodner ME, Bravender T. Teaching physicians motivational interviewing for discussing weight with overweight adolescents: theTeen CHAT randomized controlledtrial.J. Adolesc. Health2016;59:96-103. [PubMed: 27155958]

[11]. Ma J, Xiao L. Assessment of body mass index and association with adolescent preventive care in US outpatient settings. J. Adolesc. Health 2009;44:502-4. [PubMed: 19380100]

[12]. Tanda R, Salsberry P. The impact of the 2007 expert committee recommendations on childhood obesity preventive care in primary care setting in the United States. J. Pediatr. Health Care 2014;28(3):241-50. [PubMed: 23831376]

[13]. Coughlin SS. Recall bias in epidemiologic studies. J. Clin. Epidemiol. 1990;43:87-91. [PubMed: 2319285]

[14]. Harel Y, Overpeck MC, Jones DH, Scheidt PC, Bijur PE, Trumble AC, John Anderson J. The effects of recall on estimating annual nonfatal injury rates for children and adolescents. Am. J. Public Health 1994;84:599-605. [PubMed: 8154563] 
[15]. Moshiro C, Heuch I, Astrøm AN, Setel P, Kvale G. Effect of recall on estimation of non-fatal injury rates: a community based study in Tanzania. Inj. Prev. 2005;11:48-52. [PubMed: 15691990]

[16]. Bodner ME, Dolor RJ, Óstbye T, Lyna P, Alexander SC, Tulsky JA, Pollak KI. Accuracy and congruence of patient and physician weight related discussions: from Project CHAT (communicating Health: analyzing Talk). J. Am. Board Fam. Med. 2014;27:70-7. [PubMed: 24390888]

[17]. Klein JD, Graff CA, Santelli JS, Hedberg VA, Allan MJ, Elster AB. Developing quality measures for adolescent care: validity of adolescents' self-reported receipt of preventive service. Health Serv. Res. 1999;34:392-404.

[18]. Rattay KT, Fulton JE, Galuska DA. Weight counseling patterns of US pediatricians. Obes. Res. 2004;12:161-9. [PubMed: 14742855]

[19]. Bravender T, Tulsky JA, Farrell D, Alexander SC, Østbye T, Lyna P, Dolor RJ, Coffman CJ, Bilheimer A, Lin PH, Pollak KI. Teen CHAT: development and utilization of a web-based intervention to improve physician communication with adolescents about healthy weight. Patient Educ. Couns. 2013;93:525-31. [PubMed: 24021419]

[20]. Bodner ME, Bilheimer A, Gao X, Lyna P, Alexander SC, Dolor RJ, Ostbye T, Bravender T, Tulsky JA, Graves S, Irons A, Pollak KI. Studying physician-adolescent patient communication in community-based practices: recruitment challenges and solutions. Int. J. Adolesc. Med. Health 2015, doi: 10.1515/ijamh-2015-0064pii:/j/ijamh.ahead-of-print/ijamh-2015-0064/ ijamh-2015-0064.xml.

[21]. Pollak KI, Coffman CJ, Alexander SC, Østbye T, Lyna P, Tulsky JA, Bilheimer A, Dolor RJ, Lin PH, Bodner ME, Bravender T. Weight's up? Predictors of weight-related communication during primary care visits with overweight adolescents. Patient Educ. Couns. 2014;96:327-32. [PubMed: 25130793]

[22]. Klein JD, Postle CK, Kreipe RE, Smith SM, McIntosh S, Spada J, Ossip-Klein D. Do physicians discuss needed diet and nutrition health topics with adolescents? J. Adolesc. Health 2006;38:608 e1-608.e6. [PubMed: 16635776]

[23]. Liang L, Meyerhoefer C, Wang J. Obesity counseling by pediatric health professionals: an assessment using nationally representative data. Pediatrics 2012;130:67, doi:10.1542/peds. 2011-0596. [PubMed: 22665411]

[24]. Taveras EM, Sobol AM, Hannon C, Finkelstein D, Wiecha J, Gortmake SL Youths' perceptions of overweight-related prevention counseling at a primary care visit. Obesity 2007;15:831-6. [PubMed: 17426317]

[25]. Chadwick MJ, Anjum RS, Kumaran D, Schacter DL, Spiers HJ, Hassabis D. Semantic representations in the temporal pole predict false memories. Proc. Natl. Acad. Sci. U.S.A. 2016;113:10180-5, doi:10.1073/pnas.1610686113. [PubMed: 27551087]

[26]. Roediger HL, McDermott KB. Creating false memories: Remembering words not presented in lists. J. Exp. Psychol. Learn. Mem. Cogn. 1995;21:803-14.

[27]. Peddecord KM, Wang W, Wang L, Ralston K, Ly E, Friedman L, Curtis CR, Sawyer MH. Adolescents' self-reported recall of anticipatory guidance provided during well-visits at nine medical clinics in San Diego, California, 2009-2011. J. Adolesc. Health 2016;58:267-75. [PubMed: 26699230]

[28]. Edwards NM, Pettingell S, Borowsky IW. Where perception meets reality: self-perception of weight in overweight adolescents. Pediatrics 2010;125:e452-8. [PubMed: 20142281]

[29]. Lewin C, Wolgers G, Herlitz A. Sex differences favoring women in verbal but not in visuospatial episodic memory. Neuropsychology 2001;15:165-73. [PubMed: 11324860]

[30]. Marlatt KL, Farbakhsh K, Dengel DR, Lytle LA. Breakfast and fast food consumption are associated with selected biomarkers in adolescents. Prev. Med. Rep. 2016;3:49-52. [PubMed: 26844187]

[31]. Niemeier HM, Raynor HA, Lloyd-Richardson EE, Rogers ML, Wing RR. Fast food consumption and breakfast skipping: predictors of weight gain from adolescence to adulthood in a nationally representative sample. J. Adolesc. Health 2006;39:842-9. [PubMed: 17116514] 
[32]. Rausch JC, Perito ER, Hametz P. Obesity prevention, screening, and treatment: practices of pediatric providers since the 2007 expert committee recommendations. Clin. Pediatr. 2011;50(5): 434-41.

[33]. Hammig B, Jozkowski K. Health education counseling during pediatric well-child visits in physicians' office settings. Clin. Pediatr. 2015;54:752-8.

[34]. Kreuter MW, Chheda SG, Bull FC. How does physician advice influence patient behavior? Arch. Fam. Med. 2000;9:426-33. [PubMed: 10810947]

[35]. Rose SA, Poynter PS, Anderson JW, Noar SM, Conigliaro J. Physician weight loss advice and patient weight loss behavior change: a literature review and meta-analysis of survey data. Int. J. Obes. (Lond) 2012;37:118-28. [PubMed: 22450855]

[36]. Lindberg SM, Anderson CK. Improving gestational weight gain counseling through meaningful use of an electronic medical record. Matern. Child Health J. 2014;18:2188-94. [PubMed: 24627233]

[37]. O'Grady JS, Thacher TD, Chaudhry R. The effect of an automated clinical reminder on weight loss in primary care. J. Am. Board Fam. Med. 2013;26:745-50. [PubMed: 24204071] 


\section{Table 1}

Adolescent patient and physician characteristics.

\begin{tabular}{|c|c|}
\hline Adolescent $(\mathrm{n}=357)$ & n $(\%)$ or Mean (SD) \\
\hline \multicolumn{2}{|l|}{ Gender } \\
\hline Male & $151(42)$ \\
\hline Female & $206(58)$ \\
\hline \multicolumn{2}{|l|}{ Race } \\
\hline White & $128(36)$ \\
\hline Black & $186(52)$ \\
\hline Am Indian & $1(<1)$ \\
\hline Asian & $6(2)$ \\
\hline$>$ One race & $29(8)$ \\
\hline Other & $5(1)$ \\
\hline Age & $15(2)$ \\
\hline BMI z-score & $95.0(4.0)$ \\
\hline \multicolumn{2}{|l|}{ Obese } \\
\hline Yes & $233(65)$ \\
\hline No & $124(35)$ \\
\hline \multicolumn{2}{|l|}{ Physician $(n=45)$} \\
\hline \multicolumn{2}{|l|}{ Gender } \\
\hline Male & $16(36)$ \\
\hline Female & $29(64)$ \\
\hline \multicolumn{2}{|l|}{ Race } \\
\hline White & $38(84)$ \\
\hline Black & $4(9)$ \\
\hline Asian & $3(7)$ \\
\hline Age (missing $n=5$ ) & $40(9)$ \\
\hline \multicolumn{2}{|l|}{ Specialty } \\
\hline Family medicine & $7(16)$ \\
\hline Pediatrics & $38(84)$ \\
\hline
\end{tabular}

Patient Educ Couns. Author manuscript; available in PMC 2019 December 01. 


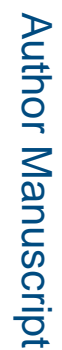

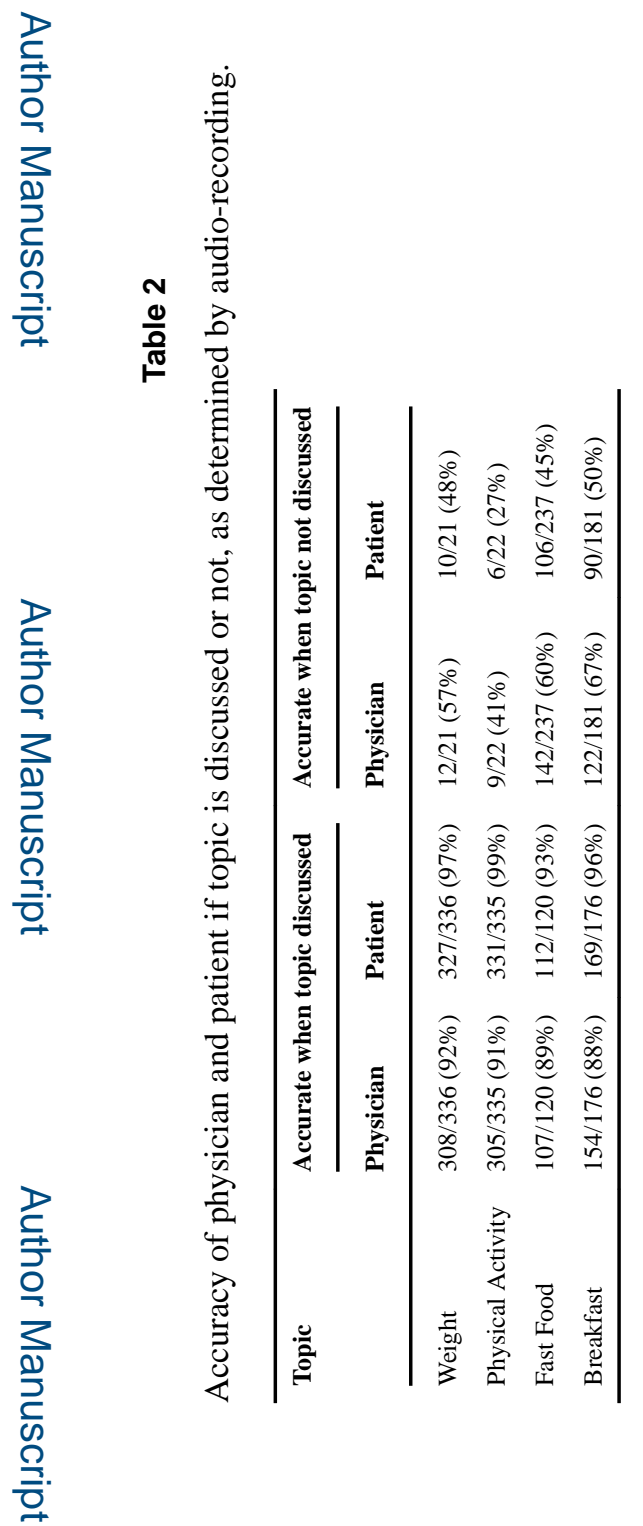

Patient Educ Couns. Author manuscript; available in PMC 2019 December 01. 


\section{Table 3}

Factors predicting adolescent accuracy for breakfast and fast food self report.

\begin{tabular}{|c|c|c|c|c|}
\hline \multirow[t]{2}{*}{ Variable } & \multicolumn{2}{|l|}{ Breakfast } & \multicolumn{2}{|l|}{ Fast food } \\
\hline & OR $(95 \% \mathrm{CI})$ & $\mathbf{p}$ & OR $(95 \% \mathrm{CI})$ & $\mathbf{p}$ \\
\hline \multicolumn{5}{|l|}{ Arm by Phase } \\
\hline \multicolumn{5}{|l|}{ Control arm } \\
\hline No MI plus Summary & $1.43(0.71-2.91)$ & $0.48^{a}$ & $2.70(1.45-5.05)$ & $0.02^{a}$ \\
\hline \multicolumn{5}{|l|}{ Report } \\
\hline No MI & 1.00 & & 1.00 & \\
\hline \multicolumn{5}{|l|}{ Intervention arm } \\
\hline MI plus Summary Report & $1.01(0.50-2.02)$ & & $0.84(0.45-1.57)$ & \\
\hline MI & 1.00 & & 1.00 & \\
\hline \multicolumn{5}{|l|}{ Physician } \\
\hline \multicolumn{5}{|l|}{ Race } \\
\hline White & $1.93(1.28-2.90)$ & 0.02 & $0.86(0.51-1.43)$ & 0.55 \\
\hline Non-white & 1.00 & & 1.00 & \\
\hline \multicolumn{5}{|l|}{ Gender } \\
\hline Male & $1.86(0.93-3.70)$ & 0.08 & $1.02(0.60-1.74)$ & 0.95 \\
\hline Female & 1.00 & & 1.00 & \\
\hline \multicolumn{5}{|l|}{ Adolescent } \\
\hline \multicolumn{5}{|l|}{ Race } \\
\hline White & $1.00(0.62-1.63)$ & 0.99 & $1.28(0.76-2.17)$ & 0.36 \\
\hline Non-white & 1.00 & & 1.00 & \\
\hline \multicolumn{5}{|l|}{ Gender } \\
\hline Male & $0.52(0.28-0.95)$ & 0.04 & $0.97(0.57-1.64)$ & 0.92 \\
\hline Female & 1.00 & & 1.00 & \\
\hline Baseline BMI z-score (in \%) & $1.00(0.95-1.05)$ & 0.88 & $0.96(0.91-1.02)$ & 0.24 \\
\hline Length of encounter (min) & $0.98(0.96-1.01)$ & 0.19 & $0.87(0.77-0.97)^{b}$ & 0.01 \\
\hline
\end{tabular}

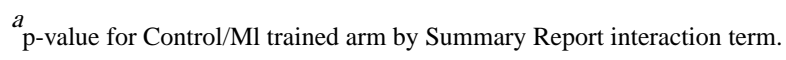

$b_{\text {Odds ratio and }} 95 \% \mathrm{Cl}$ for each five minute increase in clinical encounter. 


\section{Table 4}

Factors predicting physician accuracy for breakfast and fast food self report.

\begin{tabular}{|c|c|c|c|c|}
\hline \multirow[t]{2}{*}{ Variable } & \multicolumn{2}{|l|}{ Breakfast } & \multicolumn{2}{|l|}{ Fast food } \\
\hline & OR $(95 \% \mathrm{CI})$ & $\mathbf{p}$ & OR $(95 \% \mathrm{CI})$ & $\mathbf{p}$ \\
\hline \multicolumn{5}{|l|}{ Arm by Phase } \\
\hline \multicolumn{5}{|l|}{ Control } \\
\hline No MI plus Summary & $1.37(0.62-3.07)$ & $0.38^{a}$ & $2.04(1.28-3.25)$ & $0.05^{a}$ \\
\hline \multicolumn{5}{|l|}{ Report } \\
\hline No MI & 1.00 & & 1.00 & \\
\hline \multicolumn{5}{|l|}{ Intervention arm } \\
\hline MI plus Summary Report & $0.89(0.45-1.68)$ & & $0.82(0.38-1.77)$ & \\
\hline MI & 1.00 & & 1.00 & \\
\hline \multicolumn{5}{|l|}{ Physician } \\
\hline \multicolumn{5}{|l|}{ Race } \\
\hline White & $3.03(1.68-5.48)$ & 0.03 & $1.52(0.77-3.03)$ & 0.28 \\
\hline Non-white & 1.00 & & 1.00 & \\
\hline \multicolumn{5}{|l|}{ Gender } \\
\hline Male & $0.90(0.51-1.58)$ & 0.72 & $0.66(0.34-1.29)$ & 0.22 \\
\hline Female & 1.00 & & 1.00 & \\
\hline \multicolumn{5}{|l|}{ Adolescent } \\
\hline \multicolumn{5}{|l|}{ Race } \\
\hline White & $1.10(0.68-1.78)$ & 0.70 & $0.95(0.56-1.63)$ & 0.86 \\
\hline Non-white & 1.00 & & 1.00 & \\
\hline \multicolumn{5}{|l|}{ Gender } \\
\hline Male & $0.68(0.37-1.25)$ & 0.25 & $0.77(0.44-1.36)$ & 0.39 \\
\hline Female & 1.00 & & 1.00 & \\
\hline Baseline BMI z-score (\%) & $1.01(0.95-1.08)$ & 076 & $0.97(0.92-1.02)$ & 0.22 \\
\hline$b_{\text {Length of encounter (min) }}$ & $0.98(0.95-1.00)$ & 0.11 & $0.99(0.97-1.01)$ & 0.41 \\
\hline
\end{tabular}

Patient Educ Couns. Author manuscript; available in PMC 2019 December 01. 